\title{
Silicone Intubation with or without Balloon Dacryocystoplasty in Acquired Partial Nasolacrimal Duct Obstruction
}

\author{
ISABEL BLEYEN, WILLEM A. VAN DEN BOSCH, DAGMAR BOCKHOLTS, PAUL MULDER, \\ AND DION PARIDAENS
}

- PURPOSE: To examine if the addition of (antegrade) balloon dacryocystoplasty to bicanalicular silicone intubation affects the success rate in adults with incomplete nasolacrimal duct (NLD) obstruction.

- DESIGN: Prospective, randomized trial.

- METHODS: Seventy eyes of 70 patients with incomplete NLD obstruction and severe epiphora (Munk score grade 3 or 4) were treated randomly with dacryocystoplasty (Lacricath) and silicone intubation (Ritleng; $\mathrm{n}=$ 35, group 1; mean age, 54.4 years; standard deviation [SD], 11.8 years $)$ or silicone intubation alone $(n=35$, group 2; mean age, 53.5 years; SD, 13.1 years; $P>.05)$. The silicone tubes were removed after, on average, three months. At the visit, we assessed the grade of epiphora using the Munk score. Complete success was defined as Munk score of 0 or 1, partial success was defined as Munk score of 2, and failure was defined as Munk score of 3 or 4. Long-term Munk scores were obtained through a telephone survey nine to 76 months after surgery (mean, 43.4 in group 1 and 34.9 in group 2; $P>.05$ ). - RESULTS: Complete success was reported by 18 patients $(52 \%)$ in group 1 and by 20 patients $(57 \%)$ in group 2. Partial success was reported by one patient in group 1 and by one patient in group 2 . No improvement was reported by 15 patients (44\%) in group 1 and by 14 patients $(40 \%)$ in group 2 . Differences between the two groups proved to be not significant $(P=.8$, exact Chi-square trend test).

- CONCLUSIONS: In our patients with acquired partial NLD obstruction, treatment with a combination of antegrade dacryocystoplasty and silicone intubation was not associated with a higher success rate compared with treatment with silicone intubation alone. (Am J Ophthalmol 2007;144:776-780. () 2007 by Elsevier Inc. All rights reserved.)

\footnotetext{
Accepted for publication Jul 23, 2007.
}

From the Oculoplastic Service, The Rotterdam Eye Hospital, Rotterdam, The Netherlands (I.B., W.A.v.d.B., D.B., D.P.); and the Department of Epidemiology \& Biomedical Statistics, Erasmus Medical Centre, Rotterdam, The Netherlands (P.M.).

Inquiries to Dion Paridaens, Department of Oculoplastic and Orbital Surgery, The Rotterdam Eye Hospital, Schiedamsevest 180, 3011 BH Rotterdam, The Netherlands; e-mail: paridaens@icapi.nl

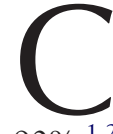

OMPLETE NASOLACRIMAL DUCT (NLD) OBSTRUCtion usually is treated with dacryocystorhinostomy (DCR), with a reported success rate of more than $90 \% .^{1,2}$ In incomplete NLD obstruction, the choice of treatment is less straightforward. ${ }^{2}$ Treatment with bicanalicular silicone intubation has been reported to yield success in $25 \%$ of patients with NLD obstruction and in only $22 \%$ after long-term follow-up, ${ }^{3,4}$ but in these studies, no distinction was made between complete and incomplete obstruction. Recently, another noninvasive treatment method, balloon dacryocystoplasty, has gained popularity, especially for treatment of congenital NLD obstruction. ${ }^{5}$ Several studies on the efficacy of dacryocystoplasty in adults with partial NLD obstruction report success rates that range from $25 \%$ to $90 \% .^{6-9}$ To our knowledge, no prospective randomized study on the results of dacryocystoplasty combined with silicone intubation vs silicone intubation alone has been reported.

\section{METHODS}

BETWEEN APRIL 1, 2000 AND DECEMBER 31, 2005, WE INCLUDED 70 patients with severe epiphora and an acquired partial NDL stenosis. All patients were treated randomly with bicanalicular silicone intubation combined with balloon dacryocystoplasty ( $\mathrm{n}=35$, group 1 ) or bicanalicular silicone intubation alone ( $n=35$, group 2 ). The mean age of patients was 54 years in group 1 (standard deviation [SD], 11.8 years) and 53 years in group 2 (SD, 13.1 years). Group 1 consisted of 31 females and four males, and group 2 consisted of 27 females and eight males. The right side was affected in 12 patients in group 1 and in 12 patients in group 2 . The left side was affected in 14 patients in group 1 and in 12 patients in group 2. Both sides were affected in nine patients in group 1 and in 11 patients in group 2 . If both sides were treated, only the left was included for randomization. There was no significant difference in mean age, gender, or right or left side involvement between the two groups $(P>.05)$.

The severity of epiphora was evaluated subjectively according to the scale proposed by Munk (Table). ${ }^{10}$ Patients were included if they reported severe epiphora (Munk grade 3 or 4 ) that lasted at least three months. Partial stenosis of the NLD was considered to be present if 
TABLE. Epiphora Grading Scale According to Munk

\begin{tabular}{cc}
\hline 0 & No epiphora \\
\hline 1 & Occasional epiphora requiring drying or dabbing less \\
than twice daily \\
2 & Epiphora requiring dabbing two to four times daily \\
3 & Epiphora requiring dabbing five to 10 times daily \\
\hline 4 & Epiphora requiring dabbing more than 10 times daily \\
& or constant tearing \\
\hline
\end{tabular}

the tear meniscus in the affected eye was clearly higher compared with that of the other eye and if the dye disappearance test results were negative. In bilateral cases of equal reported severity, we arbitrarily included the left side. Only patients who had evident tearing and had positive irrigation with reflux at syringing were included. For the purpose of this study, we additionally performed a digital subtraction dacryocystography (DCG) to confirm the clinical diagnosis of a partial stenosis of the NLD and to rule out the presence of dacryoliths.

Patients were excluded if they showed signs of pseudoepiphora (any corneal staining with fluorescein, abnormal Schirmer I test results of less than $5 \mathrm{~mm}$ after five minutes, blepharitis, or conjunctivitis), any eyelid or punctal malposition, dacryocystitis, dacryolithiasis, or any sign of inadequate tear pump functioning, such as inadequate orbicularis oculi muscle function or scarring of the lower eyelid. We also excluded patients younger than 18 years, patients with a history of lacrimal surgery, and patients with insufficient mental capacity. Informed consent was obtained of all participants. Patients in whom the introduction of a balloon catheter, silicone tube, or both was not possible technically were not included.

- SURGiCAL PROCEDURE: All procedures were performed by the same surgeon (D.P.). Under general anesthesia, the nose was packed with cotton soaked in Xylometazoline $10 \mathrm{mg} / \mathrm{ml}$. In group 1, the inferior and superior puncta were dilated. Probing was performed with a Bowman (no. 1) probe. Using the metal-to-metal technique, the presence of the probe in the inferior meatus was confirmed. The deflated lacrimal balloon catheter (Lacricath; Atrion Medical Products, Birmingham, Alabama, USA) was introduced into the superior canaliculus and was advanced into the NLD to the floor of the nose. A $3-\mathrm{mm}$ diameter balloon with a $15-\mathrm{mm}$ long working segment was used in all cases. The catheter was advanced until the superior mark on the catheter $(15 \mathrm{~mm}$ proximal to the beginning of the balloon) just reached the lacrimal punctum, meaning the most advanced position of the catheter in the NLD. The presence of the catheter in the inferior meatus was confirmed, before the balloon was inflated to a pressure of 8 bar for 90 seconds, was deflated, and then was inflated again for 60 seconds. After deflation, the lower mark of the catheter $(10 \mathrm{~mm}$ proximal to the

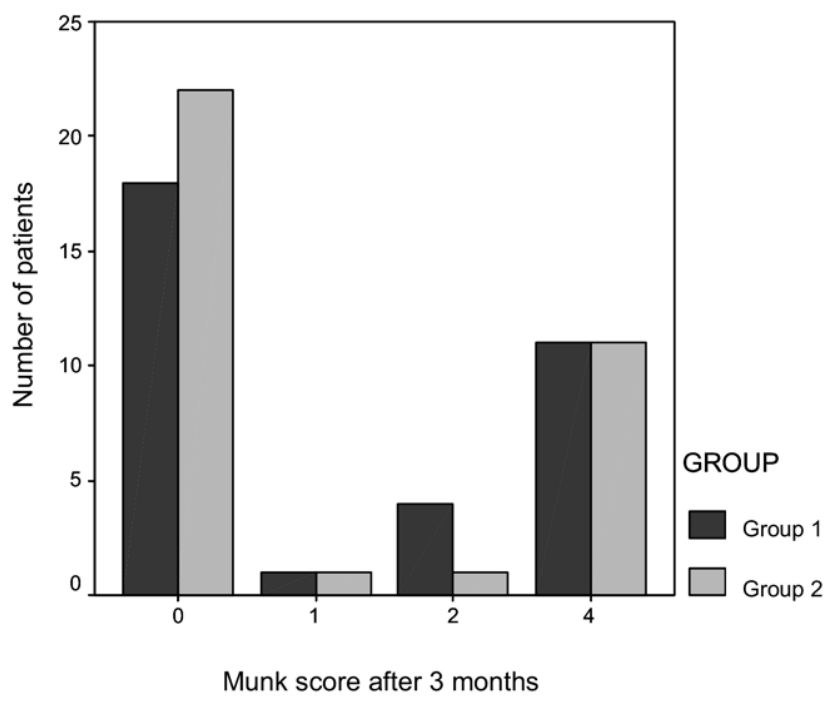

FIGURE 1. Bar graph showing the comparison between epiphora in patients with acquired partial nasolacrimal duct obstruction three months after treatment with either dacryocystoplasty combined with silicone intubation (group 1) or silicone intubation alone (group 2). The epiphora was graded according to the Munk score: 0 , no epiphora; 1 , occasional epiphora requiring drying or dabbing less than twice daily; 2 , epiphora requiring dabbing two to four times daily; 3, epiphora requiring dabbing five to 10 times daily; 4, epiphora requiring dabbing more than 10 times daily or constant tearing.

beginning of the balloon) was placed at the superior punctum, and the inflation procedure was repeated. The catheter was withdrawn only after the balloon was deflated completely. ${ }^{11}$ Next, bicanalicular silicone intubation was performed, using the Ritleng system (P. Ritleng, Issy-lesMoulineux, France). The two silicone tubes were tied together with a polypropylene 6-0 suture and was fixated to the lateral wall of the nose. ${ }^{12}$ In group 2 , bicanalicular silicone tube intubation, according to Ritleng, was performed directly after probing.

- POSTOPERATIVE MANAGEMENT: The patients were instructed to use topical dexamethasone with gentamicin thrice daily for two weeks. All patients were examined at six weeks and at approximately three months after surgery. At examination, the Munk score was assessed and slicing or extrusion was recorded. At three months, syringing was repeated and tubes were removed. Long-term outcome was evaluated with a telephone survey using the Munk scale. Complete success was defined as Munk grades 0 to 1 , partial success was defined as Munk grade 2, and failure was defined as Munk grades 3 to 4 .

\section{RESULTS}

IN BOTH GROUPS, THE MEAN MUNK SCORE WAS 4 BEFORE intervention $(\mathrm{SD}, 0.2)$. At three months after surgery, the 


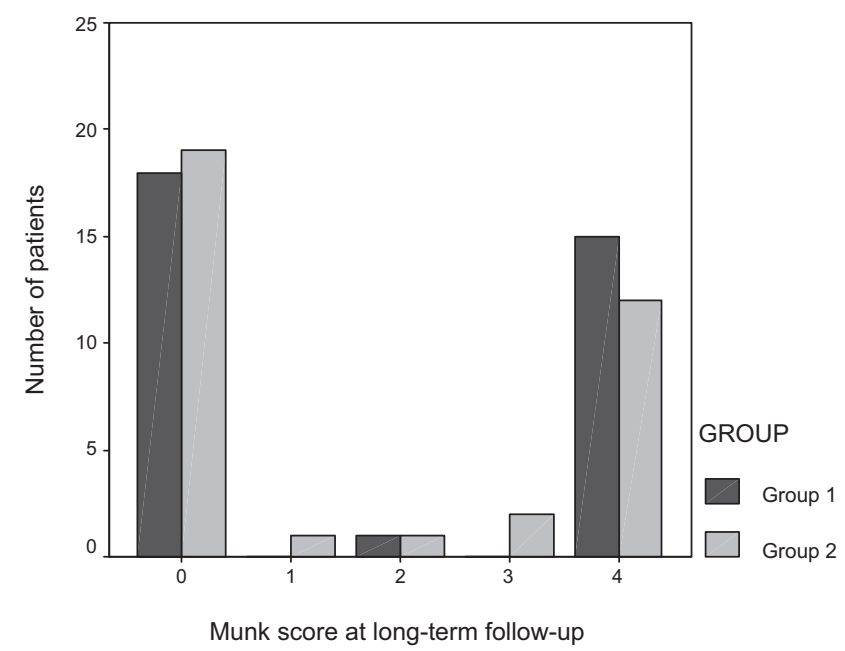

FIGURE 2. Bar graph showing the comparison between epiphora in patients with acquired partial nasolacrimal duct obstruction at long-term follow-up telephone survey after treatment with either dacryocystoplasty combined with silicone intubation (group 1) or silicone intubation alone (group 2). The epiphora was graded according to the Munk score.

\begin{tabular}{|c|c|c|c|c|c|c|c|c|}
\hline & \multicolumn{5}{|c|}{ Munk at end of follow up } & \multirow[t]{2}{*}{ Total } \\
\hline & & & 0 & 1 & 2 & 3 & 4 & \\
\hline \multirow[t]{6}{*}{ Group 1} & \multirow{6}{*}{\begin{tabular}{|l|} 
Munk \\
at 3 \\
months
\end{tabular}} & $\mathbf{0}$ & 16 & & & & 2 & 18 \\
\hline & & 1 & & & 1 & & & 1 \\
\hline & & 2 & 2 & & & & 2 & 4 \\
\hline & & 3 & & & & & & \\
\hline & & 4 & & & & & 11 & 11 \\
\hline & & Total & 18 & & 1 & & 15 & 34 \\
\hline \multirow[t]{6}{*}{ Group 2} & \multirow{6}{*}{$\begin{array}{l}\text { Munk } \\
\text { at } 3 \\
\text { months }\end{array}$} & 0 & 18 & 1 & 1 & 1 & 1 & 22 \\
\hline & & $\mathbf{1}$ & 1 & & & & & 1 \\
\hline & & 2 & & & & & 1 & 11 \\
\hline & & 3 & & & & & & \\
\hline & & 4 & & & & 1 & 10 & 11 \\
\hline & & Total & 19 & 1 & 1 & 2 & 12 & 35 \\
\hline
\end{tabular}

Munk at 3 Months: Munk score at 3 months postoperatively.

Munk at end of follow-up: Munk score at long-term follow-up

telephone survey.

FIGURE 3. Chart showing the change in epiphora (according to the Munk grading scale) in patients with acquired partial nasolacrimal duct obstruction treated with either dacryocystoplasty combined with silicone intubation (group 1, above) or silicone intubation alone (group 2, below) between three months after surgery and the long-term follow-up telephone survey.

mean Munk score was 1.6 in group $1(\mathrm{SD}, 1.8)$ and 1.3 in group $2(\mathrm{SD}, 1.9 ; P=.6$, Mann-Whitney $U$ test; Figure 1 ). In group 1 , one patient was lost to follow-up. At the telephone survey, the mean Munk score was 1.8 in group 1 $(\mathrm{SD}, 2)$ and 1.6 in group $2(\mathrm{SD}, 1.9 ; P=.7$; Figures 2 and $3)$. Complete success was reported by 18 patients (52\%) in group 1 and by 20 patients (57\%) in group 2. Partial success was reported by one patient in group 1 and by one patient in group 2. Failure was reported by 15 patients $(44 \%)$ in group 1 and by 14 patients $(40 \%)$ in group 2 . The differences between complete success, partial success, and failure between groups 1 and 2 proved not to be significant $(P=.8$, exact Chi-square trend test $)$.

Interestingly, in three patients for whom treatment failed in group 1, the outcome of syringing had changed from positive with reflux to positive without reflux. This discrepancy also was noted in seven patients in group 2 . The tubes were removed after approximately 12 weeks after surgery (mean, 12.2 weeks [SD, 5.5 weeks] in group 1 and 11.5 weeks [SD, 5.6 weeks] in group 2).

No major complications were noted in either group. Slight nasal bleeding was observed in four cases in group 1 and in three cases in group 2, which resolved spontaneously. In group 1, two silicone tubes could not be retrieved during a removal attempt. In one case, the silicone tube was removed early (after seven weeks) because of an allergic reaction. In group 2, two silicone tubes fell out after one week and in one case the silicone tube could not be retrieved. In one other case, the silicone tube had to be removed early (after five weeks) because of a slit-inferior punctum.

Follow-up from the time of surgery ranged from nine to 76 months in group 1 (mean, 43.4 months; SD, 19.6 months) and from 14 to 68 months in group 2 (mean, 34.9 months; SD, 16.6 months; $P>.1$ ).

\section{DISCUSSION}

A VARIETY OF NONINVASIVE TREATMENT METHODS THAT aim to restore patency mechanically have been proposed for the treatment of incomplete NLD obstruction. Probing was shown to have limited success of approximately $50 \%$ of adult patients. ${ }^{13}$ The reported success rate of silicone intubation without concomitant balloon dilatation in adults with NLD obstruction varies. Fulcher and associates found a $25 \%$ success rate after 15 months, ${ }^{3}$ and in a later study, Connell and associates found only a $22 \%$ success rate after seven years. ${ }^{4}$ These studies, however, did not differentiate between complete and incomplete NLD obstruction. Another study reported a 59\% complete success rate after bicanalicular silicone intubation in adults with incomplete NLD obstruction. ${ }^{14}$ This is comparable with our findings, although different definitions of complete success have been used.

Recently, dacryocystoplasty was introduced as an alternative nonincisional treatment method for incomplete NLD obstruction. It may be performed through an antegrade or through a retrograde technique. ${ }^{6-9}$ The reported 
success of dacryocystoplasty alone ranges widely, from $25 \%$ to $50 \%{ }^{6,8}$ to $90 \% .^{9,11}$ When (antegrade) dacryocystoplasty was combined with silicone intubation, two studies showed a six-month success rate of $56 \%$ to $60 \%$ in patients with incomplete NLD obstruction. ${ }^{2,15}$ Kashkouli and associates recently compared endoscopically assisted balloon dacryocystoplasty and silicone intubation with silicone intubation alone in adults in a retrospective nonrandomized case series. ${ }^{14}$ They found no difference in outcome between the two treatment methods ( $61 \%$ vs $54 \%$ ).

Although different definitions of success were used, with a complete success rate of $52 \%$ for dacryocystoplasty combined with silicone intubation and $57 \%$ for silicone intubation alone, our results are in a similar range as those reported by Kashkouli and associates. ${ }^{14}$ Our data show that the addition of antegrade dacryocystoplasty to silicone intubation does not improve the success rate. However, our study was hampered by the relatively small numbers of patients per group, which limited the statistical power. Larger series may demonstrate a difference. In addition, we used subjective measurements (Munk score) in this prospective, randomized study that compares two different methods of treatment of patients with severe epiphora. The use of the semiquantitative grading system for epiphora is not new. ${ }^{10} \mathrm{We}$ chose the subjective Munk score as the main outcome parameter because we consider it important and clinically relevant for a patient regardless of whether a procedure leads to clearance of symptoms such as a tearing eye, rather than improvement of patency of the lacrimal system. We believe its use as the main outcome parameter in this study is justified, because several studies, including ours, have shown a discrepancy between patency and clearance of symptoms of tearing, at least in a subset of patients. ${ }^{9,15,16}$ In this study, we found that the lacrimal system was patent in 10 of 16 patients with severe epiphora after treatment. We performed only irrigation tests at three months after surgery and not at long-term follow-up, when data were collected through a telephone survey. Therefore, the agreement between irrigation test results and Munk scores at long-term follow-up was not studied. The preoperative DCG was used for inclusion purposes and to rule out dacryolithiasis and was not used as an evaluation parameter.

Although the reported success rate of silicone intubation with or without dacryocystoplasty is lower than that of DCR, it holds several advantages: instead of creating a nonphysiologic bypass of the NLD, the normal anatomic pathway is reestablished and the procedure is nonincisional. ${ }^{16}$ Furthermore, in our hands, the less invasive nature of dacryocystoplasty allows for continuation of anticoagulation and antiplatelet therapy without a significant risk of bleeding. Although silicone tubing may cause complications in itself, ${ }^{16}$ these proved relatively minor in our series. Dacryocystoplasty occasionally may prove impossible because of the difficulty in introducing the catheter in the narrowed NLD.

In conclusion, our findings suggest that dacryocystoplasty does not improve the results of silicone intubation in the treatment of incomplete NLD obstruction. Further, our results with either dacryocystoplasty combined with silicone intubation or silicone intubation alone for this indication compare unfavorably with the reported outcomes after DCR. ${ }^{1,2}$

THIS STUDY WAS SUPPORTED BY THE SWOO-FLIERINGA FOUNDATION, ROTTERDAM, THE NETHERLANDS. THE AUTHORS indicate no financial conflict of interest. Involved in design and conduct of study (W.v.d.B., D.P.); collection of the data and management (D.B., I.B.); analysis of the data (P.M.); interpretation of data (I.B., W.v.d.B., D.P.); preparation of the manuscript (I.B.); review of the manuscript (W.v.d.B., D.P., P.M.); and approval of the manuscript (W.v.d.B., D.P.). This study was approved by the Institutional Review Board of the Rotterdam Eye Hospital. Proper informed consent was obtained from all patients.

\section{REFERENCES}

1. Delaney YM, Khooshabeh R. External dacryocystorhinostomy for the treatment of acquired partial nasolacrimal obstruction in adults. Br J Ophthalmol 2002;86:533535.

2. Couch SM, White WL. Endoscopically assisted balloon dacryoplasty treatment of incomplete nasolacrimal duct obstruction. Ophthalmology 2004;111:585-589.

3. Fulcher T, O'Connor MJ, Moriarty P. Nasolacrimal intubation in adults. Br J Ophthalmol 1998;82:1039-1041.

4. Connell PP, Fulcher TP, Chacko E, O'Connor MJ, Moriarty P. Long-term follow-up of nasolacrimal intubation in adults. Br J Ophthalmol 2006;90:435-436.

5. Becker BB, Berry FD, Koller H. Balloon catheter dilatation for treatment of congenital nasolacrimal duct obstruction. Am J Ophthalmol 1996;121:304-309.
6. Yazici Z, Yaziki B, Parlak M, Erturk H, Savci G. Treatment of obstructive epiphora in adults by balloon dacryoplasty. Br J Ophthalmol 1999;83:692-696.

7. Müller HM, Fries U, Berkefeld J, Thalhammer A, Kirchner J. Indications and contraindications of lacrimal duct balloon dilatation. Ophthalmologe 1999;96:97-101.

8. Lee JM, Song HY, Han YM, et al. Balloon dacryocystoplasty: results in the treatment of complete and partial obstructions of the nasolacrimal system. Radiology 1994; 192:503-508.

9. Janssen AG, Mansour K, Krabbe GJ, van der Veen S, Helder AH. Dacryocystoplasty: treatment of epiphora by means of balloon dilatation of the obstructed nasolacrimal duct system. Radiology 1994;193:453-456.

10. Munk PL, Lin DT, Morris DC. Epiphora: treatment by means of dacryocystoplasty with balloon dilatation of the nasolacrimal drainage apparatus. Radiology 1990;177:687-690. 
11. Kuchar A, Steinkogler FJ. Antegrade balloon dilatation of nasolacrimal duct obstruction in adults. Br J Ophthalmol 2001;85:200-204.

12. Müllner K. Ritleng intubation set: a new intubation system for lacrimal pathway intubation. Ophthalmologica 2000;214:237-239.

13. Bell TA. An investigation into the efficacy of probing the nasolacrimal duct as a treatment for epiphora in adults. Trans Ophthalmol Soc UK 1986;105:494-497.

14. Kashkouli MB, Beigi B, Tarassoly K, Kempster RC. Endoscopically assisted balloon dacryocystoplasty and silicone intubation versus silicone intubation alone in adults. Eur J Ophthalmol 2006;16:514-519.

15. Perry JD, Maus M, Nowinski TS, Penne RB. Balloon catheter dilation for treatment of adults with partial nasolacrimal duct obstruction: a preliminary report. Am J Ophthalmol 1998;126:811-816.

16. Kashkouli MB, Kempster R, Galloway GD, Beigi B. Monocanalicular versus bicanalicular silicone intubation for nasolacrimal duct stenosis in adults. Ophthal Plast Reconstr Surg 2005;21:142-147. 


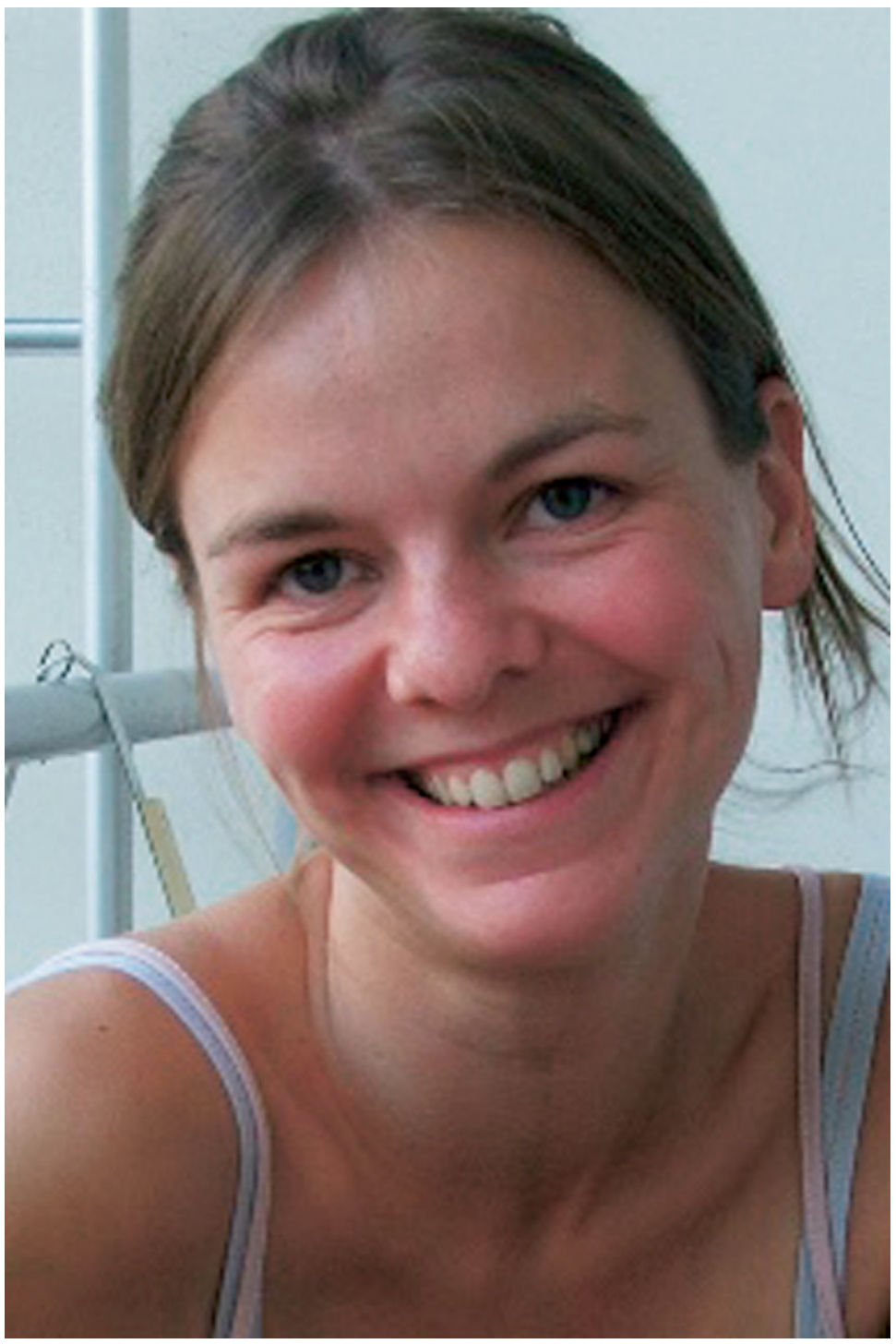

Biosketch

Isabel Bleyen completed her MD (medicine) from the University of Leuven, Belgium in 2001. She received her Certificate of Completion of Specialist Training in Ophthalmology in Germany in 2005. Dr Bleyen was a fellow in oculoplastic and orbital surgery at the Eye Hospital of Rotterdam, The Netherlands. Her plans include further fellowships in this field at both U.B.C. and the University of Montreal, Canada. 